\title{
COVID-19 and Dengue Combination Dilemma: A Case of Probable Dengue False Positivity in a COVID 19 Patient
}

\author{
MR ISLAM $^{\mathrm{a}}$, A HOSSAN $^{\mathrm{b}}$, MMN UDDIN $^{\mathrm{c}}$, MT HASAN $^{\mathrm{d}}$
}

\author{
Summary: \\ A 58-year-old diabetic and hypertensive patient showed \\ symptoms of fever for seven days with cough and irritation in \\ throat for the same duration. He did not complain of any \\ headache, shivering, confusion, breathlessness, tastelessness \\ or smell abnormalities. His first RT-PCR for coronavirus \\ disease 2019 (COVID-19) and IgM for dengue were both
}

\section{Introduction:}

In January 2020, coronavirus SARS-CoV-2 was identified as the cause of an outbreak of severe pneumonia, now known to be a complication of the coronavirus disease 2019 (Covid-19). ${ }^{1}$ Since then, the spread of covid-19 has increased exponentially, with the World Health Organization declaring a pandemic on 11 March. $^{2}$ In Bangladesh, first case was declared in Dhaka on March $8^{\text {th }}, 2020$. Bangladesh has a subtropical monsoon climate characterized by wide seasonal variations in rainfall, high temperature and humidity. Usually monsoon starts from month of June but pre monsoon rainfall which starts in March-April enhances breeding of dengue mosquito. COVID 19 and dengue share some common symptoms. So, when patient comes late and serology remains only hope to diagnose dengue, it may cause some diagnostic dilemma.

\section{Case report:}

Mr. X, 58-year-old, suffering from diabetes and hypertension for the last 12 years presented on $9^{\text {th }}$ May, 2020 with fever and cough lasting for 7 days. The highest

1. Dr. Mohammad Rafiqul Islam, Associate Professor of Medicine, Shaheed Suhrawardy Medical College.

2. Dr. Alamgir Hossan, Assistant Registrar, Shaheed Suhrawardy Medical College Hospital.

3. Dr. M M Nasir Uddin, Indoor Medical Officer, Shaheed Suhrawardy Medical College Hospital

4. Dr.Md Tanvir Hasan, Indoor Medical Officer, Shaheed Suhrawardy Medical College Hospital

Address of Correspondence: Dr. Mohammad Rafiqul Islam, Associate Professor of Medicine, Shaheed Suhrawardy Medical College. Cell: 01753199796. Mail: drrafiq73@yahoo.com positive. His first PCV value and platelet value were normal on seventh and ninth day respectively. False positive serology for dengue may happen in COVID 19 cases.

Key word: RT-PCR, COVID 19, SARS-COV-2

(J Bangladesh Coll Phys Surg 2020; 38: 133-135)

DOI: https://doi.org/10.3329/jbcps.v38i0.47440

recorded temperature was $102 \mathrm{~F}$. The fever was intermittent in nature, and was more noticeable in the evening and usually subsided with paracetamol. Cough was nonproductive with some throat irritation but had no diurnal variation or any other associated respiratory symptoms. He also complained of mild body ache for first three days of his illness. He did not complain of any headache, shivering, confusion, breathlessness, tastelessness or smell abnormalities. He also didn't complain of any bleeding spot in the skin, gum bleeding, coughing out of blood or passage of fresh blood or black tarry stool per rectum.

Upon query, patient told that he is a nonsmoker, with no history of any central chest pain and never went outside home for the last one month. His appetite was also normal. The patient also stated that he took tablet Azithromycin $500 \mathrm{mg}$ daily for seven days and tablet Fexofenadine; one tablet at night along with steam inhalation and lukewarm water gurgling for the same duration. On examination, patient was fully oriented, with temperature at $97.8 \mathrm{~F}$, mildly anemic, pulse $79 /$ minute with regular rhythm, blood pressure $120 / 80 \mathrm{~mm}$ of $\mathrm{Hg}$, respiratory rate was $16 /$ minute, jugular venous pressure was normal and oxygen saturation with pulse oximeter was $98 \%$. He had no bruise or purpuric spot in the skin. Chest examination revealed bilateral fine crepitation that changes with coughing on both mid to lower lung field. Other systemic examination revealed no abnormality. Investigations on $9^{\text {th }}$ May revealed that hemoglobin was $10.5 \mathrm{gm} / \mathrm{dl}$, PCV (packed cell volume) was 33\%, total WBC (white blood cell) count was $8660 / \mathrm{cmm}$ with a differential of $81 \%$ neutrophil, $12.2 \%$ lymphocyte and 
$6.1 \%$ monocyte. Platelet count was $317000 / \mathrm{cmm}$ and ESR (Erythrocyte sedimentation rate) was $27 \mathrm{~mm}$ in $1^{\text {st }}$ hour. Urine R/E revealed 0-2 pus cell/ HPF, no cast, sugar or protein were present. His Serum Creatinine was 0.83/ $\mathrm{mg} / \mathrm{dl}$. As patient had fever, body ache and early raining of monsoon started, Dengue antibody was done with the suspicion of Dengue fever. Antibody for Dengue Ig $\mathrm{M}$ and $\mathrm{Ig} \mathrm{G}$ were positive.

In this COVID 19 pandemic, patient also had fever and cough. That's why we have done RT-PCR (reverse transcription polymerase chain reaction) for COVID 19 on $9^{\text {th }}$ May and report came on $10^{\text {th }}$ May with positive result. On $11^{\text {th }}$ May, CBC (Complete blood count) revealed Hemoglobin $10.8 \mathrm{gm} / \mathrm{dl}$, PCV 33.4\%, WBC 8000/ Cmm, Neutrophil 70\%, Lymphocyte 24\%, Monocyte 4\%, platelet count $439000 / \mathrm{Cmm}$ and ESR was $27 \mathrm{~mm}$ in $1^{\text {st }}$ hour. His D-dimer was $3117 \mathrm{ng} / \mathrm{mL}(<500 \mathrm{ng} / \mathrm{mL})$, Serum ferritin 813ng/mL (20-300 ng/mL), Serum LDH 249 U/L $(<248 \mathrm{U} / \mathrm{L})$ and CRP was $156 \mathrm{mg} / \mathrm{L}(<5 \mathrm{mg} / \mathrm{L})$. Chest X ray posterior anterior view revealed ill-defined opacity in left upper zone as well as middle and lower zone in both lung field (Figure 1). Patient was finally diagnosed as a case of COVID 19 and treated accordingly. He recovered with standard protocol treatment.

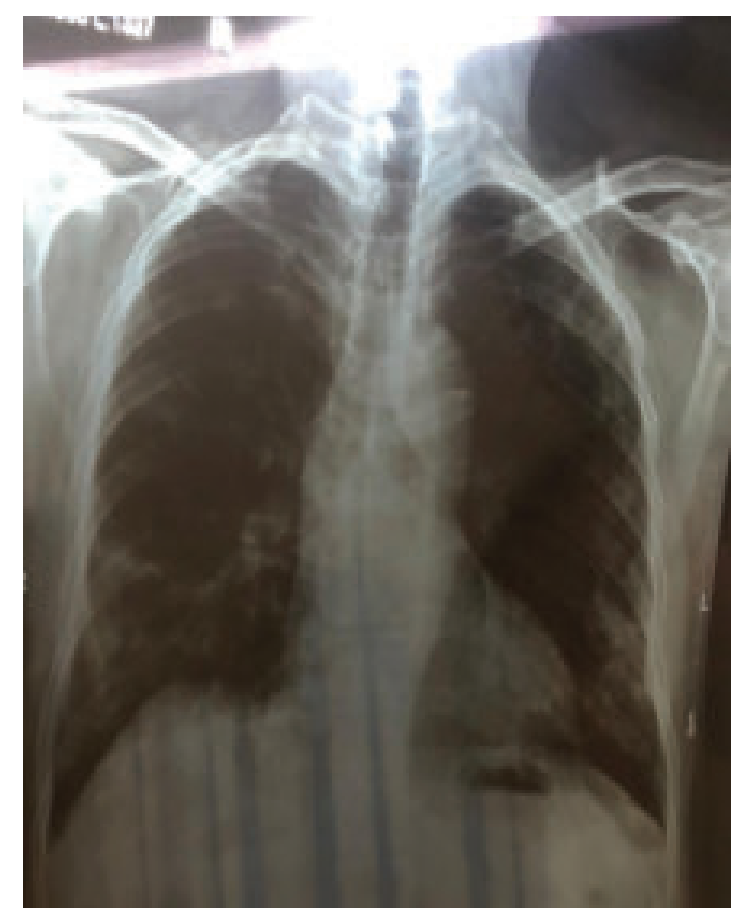

Fig.-1: Chest X ray of Patient.

\section{Discussion:}

Since Dec 8, 2019, several cases of pneumonia of unknown etiology have been reported in Wuhan, Hubei province, China. ${ }^{3-5}$ Some patients developed serious complication like ARDS, acute respiratory failure, sepsis and sepsis with multi organ failure. The virus is highly contagious and has the capability of transmission from symptomatic, pre-symptomatic and asymptomatic patients. ${ }^{6}$ As a result, it is spreading all over the world. Bangladesh officially declared its first three cases of COVID 19 on $8^{\text {th }}$ March $2020^{7}$ and as of $18^{\text {th }}$ May 2020, according to the Institute of Epidemiology, Disease Control and Research (IEDCR), there are 23,870 confirmed COVID-19 cases in Bangladesh, including 349 related deaths. ${ }^{8}$

Our patient developed fever, cough and mild body ache. According to current pandemic protocol he was diagnosed clinically a case of COVID 19. He went for RT-PCR for COVID 19 and it was positive. Bangladesh has a subtropical monsoon climate characterized by wide seasonal variations in rainfall, high temperature and humidity. Usually monsoon starts from month of June but pre monsoon rainfall which starts in March-April enhances breeding of dengue mosquito. During 20152017, in the pre-monsoon season, the dengue cases were reported to be more than seven times higher compared to the previous 14 years ${ }^{9}$. In this background and as patient presented after 7 days of illness, dengue antibody tests were sent. Both Ig M and IgG for dengue were positive which means patient was also suffering from probable dengue infection.

However, the patient had no typical clinical presentation of dengue fever like high rise of temperature, severe headache, body ache or any bleeding episode. Instead, his chest X ray was typical of COVI 19. On day 7, his PCV was $33 \%$ and day 9 it was $33.4 \%$. Though patient had $\operatorname{IgM}$ for dengue was positive, on $7^{\text {th }}$ and $9^{\text {th }}$ day of illness his WBC count was $8660 / \mathrm{Cmm}$ and $8000 / \mathrm{Cmm}$ respectively and platelet count was $317000 / \mathrm{Cmm}$ and $439000 / \mathrm{Cmm}$ respectively. CBC in dengue patients change by the day of the fever, specifically on days 3 to 8 , starting with progressive leukopenia followed by thrombocytopenia and hemoconcentration due to plasma leakage. ${ }^{10,11}$ In our case there was no hemoconcentration and no thrombocytopenia.

As Patient had IgG for Dengue was positive on day 7, it was obvious that he had previous dengue fever. On 
this background, second infection with different strain must be severe in terms of clinical and laboratory parameter. So, it is very much likely that the dengue serology of our patient was false positive on the basis of all these clinical backgrounds. False positive serology for dengue was reported in Singapore in COVID 19 cases. $^{12}$ It would have been better if we could do antibody titer of Ig G for dengue. We couldn't do it due to lack of interest from patient party. Patient was given treatment of COVID 19 treatment as per protocol of Bangladesh COVID 19 guideline. Patient responded well and recovered. So, we are reporting the case as false positive for dengue antibody which may confuse both patients and physicians about dengue COVID 19 combination.

\section{References:}

1. Zhou P, Yang XL, Wang XG, Hu B, Zhang L, Zhang W, et al. A pneumonia outbreak associated with a new coronavirus of probable bat origin. Nature 2020; 579:270-3.

2. World Health Organization. WHO director-general's opening remarks at the media briefing on covid-19. 11 March 2020. https://www.who.int/dg/speeches/detail/whodirector-generals-opening-remarks-at-the-media-briefingon-covid-19-11-march-20202.

3. Lu H, Stratton CW, Tang YW. Outbreak of pneumonia of unknown etiology in Wuhan China: the mystery and the miracle. J Med Virol 2020; published online Jan 16. DOI: $10.1002 /$ jmv. 25678

4. Hui DS, Azhar EI, Madani TA, Ntoumi F, Kock R, Dar O, et al. The continuing 2019-nCoV epidemic threat of novel coronaviruses to global health - the latest 2019 novel coronavirus outbreak in Wuhan, China. Int $J$ Infect Dis 2020; 91: 264-66.

5. Huang C, Wang Y, Li X, Ren L, Zhao J, Hu Y, et al. Clinical features of patients infected with 2019 novel coronavirus in Wuhan, China. Lancet 2020; 395:497-506

6. World Health Organization. ( 2020) . Novel Coronavirus ( 2019-nCoV) : situation report73. https://www.who.int/docs/ default-source/coronaviruse/situation-reports/20200402sitrep-73-covid-19.pdf?sfvrsn=5ae25bc7_2

7. WHO Bangladesh COVID-19 Situation Report \#10. https:/ /www.who.int/bangladesh/emergencies/coronavirus-disease(covid-19)-update/coronavirus-disease-(covid-2019)bangladesh-situation-reports

8. WHO Bangladesh COVID-19 Situation Report \#12. https:/ /www.who.int/bangladesh/emergencies/coronavirus-disease(covid-19)-update/coronavirus-disease-(covid-2019)bangladesh-situation-reports

9. Mutsuddy p, Jhora ST, Shamsuzzaman AKM, Kaiser SKG, Khan MNA. Dengue Situation in Bangladesh: An Epidemiological Shift in terms of Morbidity and Mortality. Canadian Journal of Infectious Diseases and Medical Microbiology. 2019;1-12.

10. Oliveira EC, Pontes ER, Cunha RV, Froes IB, Nascimento D. Hematological abnormalities in patients with dengue. Rev Soc Bras Med Trop. 2009;42(6):682-5.

11. Ali N, Usman M, Syed N, Khurshid M. Haemorrhagic manifestations and utility of haematological parameters in dengue fever: a tertiary care Centre experience at Karachi. Scand J Infect Dis. 2007;39(11-12):1025-8

12. Yan G, Lee CK, Lam LTM, Yan B, Chua YX, Lim AYN et al. Covert COVID-19 and false-positive dengue serology in Singapore. Lancet Infect Dis. 2020; 20:536. 